\title{
Factors associated with the appropriate use of asthma drugs
}

\author{
Marie-Sophie Jobin BPharm MSc ${ }^{1,2}$, Jocelyne Moisan PhD ${ }^{1,2}$, Yves Bolduc MD ${ }^{3}$, \\ Eileen Dorval BPharm ${ }^{4}$, Louis-Philippe Boulet $\mathrm{MD}^{5}$, Jean-Pierre Grégoire $\mathrm{PhD}^{1,2}$
}

M-S Jobin, J Moisan, Y Bolduc, E Dorval, L-P Boulet, J-P Grégoire. Factors associated with the appropriate use of asthma drugs. Can Respir J 2011;18(2):97-104.

BACKGROUND: When used properly, asthma drugs can reduce asthmarelated morbidity and mortality.

OBJECTIVE: To assess the use of asthma drugs, and to identify factors associated with appropriateness of use among patients 12 to 45 years of age. METHODS: Asthmatic patients were interviewed about their asthma drug(s) use and the factors potentially associated with appropriateness of use according to the 2003 Canadian Asthma Consensus Conference guidelines. To determine the factors associated with the appropriate use of asthma drugs, a multivariate logistic regression model was built using a stepwise procedure, and ORs and associated $95 \%$ CIs were calculated.

RESULTS: Of the 349 study participants, 43 (12.3\%) reported appropriate use of their asthma drugs. Respondents who were more likely to report appropriate use were patients with sound knowledge of their asthma drugs (OR 2.61 [95\% CI 1.29 to 5.29]), those in good, very good or excellent self-perceived health (OR 3.37 [95\% CI 1.31 to 8.71]), those who had consulted a specialist during the preceding year (OR 2.28 [95\% CI 1.05 to 4.97]) and those who declared themselves short of drugs due to a lack of money (OR 2.78 [95\% CI 1.26 to 6.17]).

CONCLUSIONS: Results of the present study suggested that recommendations in the current guidelines regarding the appropriate use of asthma medications are being poorly implemented. Educational interventions with the aim of improving quality of care and knowledge about asthma drugs should be offered.

\section{Key Words: Asthma; Drug therapy; Drug use; Health behaviour}

A sthma is a chronic respiratory illness affecting up to $8.4 \%$ of the Canadian population (1) and approximately 300 million people worldwide (2). Despite improvements in the understanding of the physiopathology of asthma and in the availability of effective pharmacological agents, a recent multinational study of asthmatic subjects on regular maintenance therapy (3) revealed that only $28 \%$ reported their disease as being adequately controlled. Suboptimal control of asthma may incur the substantial use of health care resources $(4,5)$. In Canada, direct and indirect costs associated with asthma were reported to be between $\$ 540$ million and $\$ 648$ million in 1990 (6). In the United States, the asthma burden was estimated to be $\$ 12.7$ billion in 1998 (7).

Asthma can be effectively treated and adequately controlled with the appropriate use of asthma medication and nonpharmacological measures (8). Despite the widespread distribution of asthma treatment guidelines, the inappropriate use of asthma drugs persists. Many studies focusing on usage have indicated that asthmatic patients underuse inhaled corticosteroids (8-16) and overuse short-acting beta-2 agonists $(9,10,12,13,15,16)$. In most of these studies, assessment of appropriateness of use focused on short-acting beta- 2 agonists or inhaled corticosteroids individually $(9,15-17)$, or on both concurrently

\section{Les facteurs associés à l'utilisation judicieuse des médicaments contre l'asthme}

HISTORIQUE : Lorsqu'ils sont bien utilisés, les médicaments contre l'asthme peuvent réduire la morbidité et la mortalité liées à l'asthme. OBJECTIF : Évaluer l'utilisation des médicaments contre l'asthme et repérer les facteurs associés au bien-fondé de leur utilisation chez les patients de 12 à 45 ans.

MÉTHODOLOGIE : Les chercheurs ont interviewé des patients asthmatiques au sujet de leur utilisation de médicaments contre l'asthme et des facteurs susceptibles d'être associés au bien-fondé de cette l'utilisation selon les lignes directrices 2003 de la Conférence canadienne de consensus sur l'asthme. Pour déterminer les facteurs associés à l'utilisation judicieuse de médicaments contre l'asthme, les chercheurs ont établi un modèle de régression logistique multivariée à l'aide d'une intervention progressive et ont calculé les RRR et les IC $95 \%$.

RÉSULTATS : Parmi les 349 participants à l'étude, 43 (12,3\%) ont déclaré une utilisation judicieuse de leurs médicaments contre l'asthme. Les répondants les plus susceptibles de déclarer une telle utilisation étaient ceux qui connaissaient très bien leurs médicaments contre l'asthme (RRR 2,61 [95 \% IC 1,29 à 5,29]), ceux qui percevaient leur santé comme bonne, très bonne ou excellente (RRR 3,37 [95 \% IC 1,31 à 8,71]), ceux qui avaient consulté un spécialiste pendant l'année précédente (RRR 2,28 [95\% IC 1,05 à 4,97]) et ceux qui déclaraient manquer de médicaments par manque d'argent (RRR 2,78 [95 \% IC 1,26 à 6,17]).

CONCLUSIONS : D'après les résultats de la présente étude, les recommandations des lignes directrices portant sur l'utilisation judicieuse des médicaments contre l'asthme sont peu mises en œuvre. Il faudrait donc offrir des interventions pédagogiques visant à améliorer la qualité des soins et les connaissances sur l'asthme.

$(10,11,13)$, with no attempt to assess the use of other asthma drugs. To our knowledge, only one study (14) assessed the appropriate use of overall asthma drug treatment. It also appears that most studies focusing on factors associated with the optimal or nonoptimal use of asthma drugs have taken the same approach $(9,13,15-17)$.

To the best of our knowledge, no study to date has been undertaken to specifically identify the factors associated with appropriateness of self-reported use of overall anti-asthma therapy. This, despite the fact that an improved understanding of these factors might enable health care providers to assist their patients in better managing their therapeutic regimen and, thereby, attain optimal therapeutic outcome. The present cross-sectional study was designed to assess the appropriateness of self-reported use of asthma drugs by individuals 12 to 45 years of age, and to assess the effects of an array of potential predisposing, enabling and reinforcing factors associated with the appropriate use of asthma medication.

\section{METHODS}

Participants were recruited across the province of Quebec through 42 community pharmacists. The pharmacists screened their pharmacy database to identify individuals 12 to 45 years of age who were dispensed at

${ }^{1}$ Faculté de pharmacie, Université Laval, Québec; ${ }^{2}$ URESP, Centre de recherche FRSQ du Centre hospitalier affilié universitaire de Québec; ${ }^{3}$ Centre de santé et de services sociaux de Lac-Saint-Jean-Est, Alma; ${ }^{4}$ Pharmacist and Disease Management Consultant; ${ }^{5}$ Institut universitaire de cardiologie et de pneumologie de Québec, Québec

Correspondence: Dr Jocelyne Moisan, Unité de recherche en santé des populations, Centre hospitalier affilié universitaire de Québec, 1050, chemin Ste-Foy, Québec, Québec G1S 4L8. Telephone 418-682-7511 ext 4654, fax 418-682-7962,

e-mail jocelyne.moisan@pha.ulaval.ca 
least one anti-asthma drug in the previous six months, and contacted them by telephone. Because the target population was only persons with mild to severe asthma, eligible individuals were required to report to the pharmacist that they were using a short-acting beta- 2 agonist more than three times per week, a corticosteroid (inhaled or oral) regardless of how often, and that a physician had diagnosed them with asthma. Pregnant women, individuals already participating in a respiratory study or individuals with another respiratory illness were excluded. Eligible individuals expressing interest in enrolling in the study were provided with a brief document outlining the research project by their pharmacist. They were subsequently asked to read, sign and mail a consent form back to the study centre.

Within a mean of 19 days after receiving their signed consent, a research assistant gathered information from participants on all study variables using a structured, pretested telephone questionnaire. Participants were asked to name all of their asthma drugs. For each drug reported to be used, they were then asked the following question: "How many days did you use your medication last week?"; "On the days of use, how many times did you make use of your medication?" (If the number of times was not the same for each day, participants were asked the number of times they had used it on the most recent day of use); and "How many times did you use your medication before doing exercise last week?" Finally, using open-ended or multiple-choice questions, information regarding 17 predisposing, 21 enabling and three reinforcing factors (18) potentially associated with appropriate use of asthma drugs was obtained (Table 1).

To define the appropriate use of asthma drugs, the study investigators (MSJ, JM, LPB and JPG) developed a set of 12 hierarchical criteria based on the 2003 Canadian Asthma Consensus Conference guidelines (19). Based on this set of criteria and their answers to the questions on drug use, participants were classified into two groups: appropriate use or inappropriate use. Whenever one criterion was not met, use was considered to be inappropriate and, therefore, subsequent criteria were not applied. Participants were regarded to be appropriately using their asthma drugs if they reported the following:

1. Taking at least two asthma drugs;

2. Taking a controller (an inhaled corticosteroid or a leukotrienereceptor antagonist);

3. Taking a quick-relief bronchodilator (a short-acting beta-2 agonist or formoterol);

4. Having used their controller daily in the seven days preceding the interview;

5. Having used their controller for the same number of times every day and at an adequate frequency based on product monographs;

6. Having used their quick-relief bronchodilator less than four times in the week preceding the interview, excluding doses taken just before exercising;

7. Having used their add-on therapy daily in the seven days preceding the interview (if applicable);

8. Having used their add-on therapy for the same number of times every day and at an adequate frequency based on product monographs (if applicable);

9. They did not use nedocromil or sodium cromoglycate or ipratropium;

10. They did not use theophylline or an oral steroid without using a long-acting beta-2 agonist or a leukotriene-receptor antagonist;

11. They did not use a long-acting beta-2 agonist or theophylline without using an inhaled corticosteroid; and

12. They used no more than one drug in a pharmacological class.

First, the proportion of participants using asthma drugs appropriately was calculated. Second, participant characteristics were described using frequency distributions. Subsequently, a bivariate logistic regression analysis of the association between the appropriate use of asthma drugs and each of the predisposing, enabling and reinforcing factors was performed, followed by a multivariate logistic regression analysis to calculate adjusted ORs and their associated 95\% CIs. Variables were entered in the model using a stepwise procedure (entry level of 0.10 and exit level of 0.15), and only those variables statistically significant at an alpha level of 0.05 were retained in the final model. Multicollinearity was assessed using the procedure described by Belsley et al (20). All analyses were conducted using SAS version 9.1 (21).

The present study was approved by the Centre hospitalier affilié universitaire de Québec's Ethics in Research Committee (Quebec, Quebec).

\section{RESULTS}

A total of 1166 individuals were identified from the pharmacy databases and called by the pharmacists. Although 606 of these individuals satisfied the enrollment criteria, 105 declined participation. Of the 501 individuals expressing interest in paticipating, 349 provided informed, signed consent and were interviewed, yielding a response rate of $57.6 \%$.

According to the criteria, a total of $43(12.3 \%)$ participants used their asthma drugs appropriately (Figure 1). Of the 41 factors considered, four were retained in the final multivariate logistic regression model (Table 2). Participants with sound knowledge of their asthma drugs were more likely to use them appropriately (OR 2.61 [95\% CI 1.29 to 5.29]), as were those with good, very good or excellent selfperceived health (OR 3.37 [95\% CI 1.31 to 8.71]), those who had consulted a specialist during the preceding year for asthma-related problems (OR 2.28 [95\% CI 1.05 to 4.97]) and those who declared themselves as having been short of drugs due to a lack of money (OR 2.78 [95\% CI 1.26 to 6.17]).

Because the criteria were stringent, the data were re-analyzed, allowing five, six or seven days of use per week for controller (criterion 4) and add-on therapy (criterion 7), and ignoring the number of times drugs were taken each day (criteria 5 and 8 ). In light of these changes, the proportion of appropriate use increased by $4 \%$ - from $12.3 \%$ to $16.3 \%$. Variables associated with appropriate use remained unchanged (data not shown).

\section{DISCUSSION}

The present study assessed the appropriateness of self-reported use of asthma drugs based on an innovative set of criteria. We observed that only $12.3 \%$ of asthmatic patients used their asthma drugs according to Canadian Asthma Consensus Conference guidelines. Our results corroborate the findings of previous studies $(8-16,22)$ - that the use of asthma drugs by asthmatic patients is not optimal. The major original finding of the present study was the identification of four key factors associated with the appropriate use of asthma drugs. First, the finding that patients who are well informed about both the role and onset of action of their drugs are more likely to use them appropriately, is consistent with results of previous studies in which insufficient knowledge about drugs has been associated with poorer adherence to daily use of inhaled corticosteroids (23), or those with poorly controlled asthma (5).

In our study, individuals reporting good, very good or excellent self-perceived health were more likely to report appropriate use of their asthma drugs. These results are consistent with those of a recent retrospective study conducted in the United States (22) in which individuals who appropriately used short-acting beta-2 agonists defined as the acquisition of less than 225 defined daily doses of a short-acting beta- 2 agonist per year in conjunction with more than 45.625 defined daily doses of inhaled corticosteroid per year - reported better self-perceived overall health (22).

Individuals who reported having been short of drugs in the previous year due to a lack of money were more likely to have used their asthma drugs appropriately. This result was not expected, although it was previously shown that economical access to a drug treatment is associated with better adherence, particularly in hypertension (24). In the current study, appropriateness of use was defined based on the fulfillment of 12 criteria, some of which specifically related to the self-reported use of medications in the seven days preceding the interview. It is, therefore, plausible that people who report having been short of drugs in the 
TABLE 1

Factors potentially associated with the appropriate use of asthma drugs

\begin{tabular}{|c|c|}
\hline Independent variable & Brief description \\
\hline \multicolumn{2}{|l|}{ Predisposing factors } \\
\hline Age & Date of interview - date of birth; dummy coded (age [years] younger than 20, 20 to 29, or 30 and older) \\
\hline Sex & Confirmed at interview \\
\hline Educational level* & $\begin{array}{l}\text { Highest completed educational level. Two categories (none, elementary school or high school not completed; high school } \\
\text { completed, college or university) }\end{array}$ \\
\hline Main occupation* & Two categories (student/worker or other) \\
\hline Family income* & $\begin{array}{l}\text { Low, high or undetermined (defined as low for family with } 1 \text { or } 2 \text { persons if below } \$ 30,000 / \text { year, for family with } 3 \text { to } 4 \text { persons if } \\
\text { below } \$ 40,000 \text { /year, or for family with } 5 \text { or more persons if below } \$ 60,000 / y e a r \text { ) }\end{array}$ \\
\hline Body mass index (BMI) & $\begin{array}{l}\text { Height and weight were asked of participants. BMI calculated by dividing weight in kg by height in metres squared, then dummy } \\
\text { coded using WHO categories (28) }\left(24.9 \mathrm{~kg} / \mathrm{m}^{2} \text { or less, } 25.0 \mathrm{~kg} / \mathrm{m}^{2} \text { to } 29.9 \mathrm{~kg} / \mathrm{m}^{2} \text { or } 30 \mathrm{~kg} / \mathrm{m}^{2} \text { or higher) for individuals }\right. \\
18 \text { to } 45 \text { years of age and using CDC BMI charts (29) for individuals } 12 \text { to } 17 \text { years of age }\end{array}$ \\
\hline
\end{tabular}

Perception of health*

Perception of asthma severity

Measured by a 5-item question, range: poor to excellent, and then dichotomized (fair or poor; good, very good or excellent)

Measured by a 5-item question, range: very mild to very severe, and then dichotomized (moderate, severe or very severe; very mild or mild).

Beliefs about asthma ${ }^{\dagger}$

Six yes/no questions. Number of positive answers per participant computed. Participants then dichotomized using median as cut-off point $^{\ddagger}$ (median $\left.=4\right)$

Attitudes towards asthma ${ }^{\dagger}$

Nine yes/no questions. Number of positive answers per participant computed. Participants then dichotomized using median as cut-off point ${ }^{\ddagger}$ (median $=7$ )

Self-confidence

Knowledge about:

Two yes/no questions referring to confidence in personal ability to contribute to the management of illness. Number of positive answers per participant computed. Participants then dichotomized using median as cut-off point ${ }^{\S}(\operatorname{median}=2)$

Scores computed adding 1 point for each good answer. Missing values and "I don't know" answers coded as incorrect answer. Each variable then dichotomized using median as cut-off point

Asthma physiopathology Asthma symptoms

Asthma triggers Three true/false questions ${ }^{\S}$ (median $=3$ )

Two true/false questions ${ }^{\S}($ median $=2)$

Three true/false questions ${ }^{\ddagger}($ median $=2)$

Six true/false questions ${ }^{\ddagger}($ median $=4)$

Asthma self-management

Knowledge about asthma drugs

Number of years with asthma

Enabling factors

Perceived effects of treatment

Perception of risk of dying due to asthma if drug is taken as directed by physician

Perception of risk of dying due to asthma if drug is not taken as directed by physician

Self-reported side effects

Short of drugs due to a lack of money

Ease in obtaining appointments with physicians

Ease in obtaining information on asthma from :

Pharmacist

Nurse

Respiratory therapist

Other health professionals

Possession of a written action plan

Daily or weekly use of peak

flow meter

Vaccination against influenza

in past 12 months

Vaccination against pneumonia

in past 12 months

Ever tested for allergies

Four true/false questions for each drug mentioned by participant. Knowledge score for each drug computed on scale of 0 to 4 , with 4 a perfect score. A mean asthma drug(s) knowledge score computed for each participant. Participants subsequently dichotomized according to said score using median as cut-off point ${ }^{\ddagger}$ (median $=2.67$ )

Age at the interview - age (years) at first diagnosis of asthma; continuous

Perception of drug efficacy measured for each drug mentioned by participants using a 4-item question (no effect to a lot of effect). Dichotomized by grouping together those individuals who answered "a lot of effect" for all their drugs

Assessed for each drug mentioned by participant using a 4-item question (range: no risk to very high risk). Dichotomized by grouping individuals who answered "no risk" for all of their drugs

Assessed for each drug mentioned by participant using a 4-item question (range: no risk to very high risk). Dichotomized by grouping individuals who responded "moderate risk", "high risk" or "very high risk" for all of their drugs

Assessed for each drug mentioned by participant (yes/no). Dichotomized by grouping individuals not reporting adverse effects for any drugs

For each drug mentioned by participant assessed by a yes/no question, as to whether they had been short of drug during preceding year due to a lack of money. Dichotomized by grouping individuals who responded "no" for all of their drugs

Individuals reporting an appointment with a physician during preceding year asked about ease in obtaining same (4-item question, range: very difficult to very easy), then dichotomized (very easy/easy; difficult, very difficult or physician not seen during preceding year)

Each item assessed as follows: individuals reporting having seen a health professional the preceding year were asked about ease in obtaining information on asthma from said professional (4-item question, range: very difficult to very easy) and then dichotomized (very easy/easy; very difficult, difficult or professional not seen during preceding year)

Assessed using 5 yes/no questions: ever received written instructions from a physician, nurse, pharmacist, respiratory therapist or other health professional? Dichotomized by grouping those responding "yes" to any of these questions

Two questions: Participant uses a peak flow meter (yes/no). If "yes", participant assessed for peak flow meter use: every day/ approximately once a week/once a month/less than once a month. Dichotomized by grouping individuals responding "yes" to the first question and "every day" or "approximately once a week" to the second question

One yes/no question

One yes/no question

One yes/no question

Continued on next page 
TABLE 1 - CONTINUED

Factors potentially associated with the appropriate use of asthma drugs

\begin{tabular}{|c|c|}
\hline Independent variable & Brief description \\
\hline \multicolumn{2}{|l|}{ Enabling factors } \\
\hline Lung function test & $\begin{array}{l}\text { Two questions: Did you have a lung function test during the past } 12 \text { months? (yes/no). If "no", assessed for ever having lung } \\
\text { function test (yes/no). Dichotomized by grouping those responding "yes" to either question }\end{array}$ \\
\hline $\begin{array}{l}\text { Ever obtained written } \\
\text { information on asthma from } \\
\text { health professionals }\end{array}$ & $\begin{array}{l}\text { Five yes/no questions: Have you ever received written information on asthma from: a physician, a nurse, a pharmacist, } \\
\text { a respiratory therapist or other health professional? } \\
\text { Dichotomized by grouping individuals responding "yes" to any question }\end{array}$ \\
\hline $\begin{array}{l}\text { Ever had inhalation technique } \\
\text { verified by health professional }\end{array}$ & $\begin{array}{l}\text { Five yes/no questions: Has your inhalation technique ever been checked by: a physician, a nurse, a pharmacist, a respiratory } \\
\text { therapist or other health professional? Dichotomized by grouping individuals responding "yes" to any question }\end{array}$ \\
\hline $\begin{array}{l}\text { Attended an asthma education } \\
\text { clinic }\end{array}$ & $\begin{array}{l}\text { Three yes/no questions: At any time last year, did a doctor or other health professional suggest you meet with an asthma } \\
\text { educator? If yes, did you do so? At any time in the past year did you attend an asthma education clinic run by a doctor or other } \\
\text { health professional? Dichotomized by grouping individuals responding "yes" to the first two questions or "yes" to the third }\end{array}$ \\
\hline $\begin{array}{l}\text { Consulted general practitioner } \\
\text { during preceding year for } \\
\text { asthma-related problems }\end{array}$ & $\begin{array}{l}\text { Two questions: During the past year, did you consult a physician about your asthma or an asthma-related problem, in a clinic, at } \\
\text { a CLSC", at an emergency room or during a hospitalization? If answer "yes", physician type assessed using 3-item question } \\
\text { (general practitioner, specialist or both). Participants responding "yes" to first question and "general practitioner" or "both" to } \\
\text { second question, were considered to have consulted a general practitioner during the previous year for asthma-related } \\
\text { problems }\end{array}$ \\
\hline $\begin{array}{l}\text { Consulted specialist during the } \\
\text { preceding year for asthma- } \\
\text { related problems }\end{array}$ & $\begin{array}{l}\text { Two questions: During the past year, did you consult a physician about your asthma or an asthma-related problem, in a clinic, a } \\
\text { CLSC", at an emergency room or during a hospitalization? If answer "yes", physician-type assessed using 3-item question } \\
\text { (general practitioner, specialist or both types of physician). Participants responding "yes" to first question and "specialist" or } \\
\text { "both types of physicians" to second question, were considered to have consulted a specialist during the previous year for } \\
\text { asthma-related problems }\end{array}$ \\
\hline
\end{tabular}

Reinforcing factors

Coherence of information

Coherence of the information provided by health professionals measured by two yes/no questions: Do health professionals seem to agree about your asthma treatment? Do health professionals seem to agree about things to do concerning your asthma? "Yes" answer to both questions considered to be coherence

Satisfaction with physician care Two 4-item questions on satisfaction with information given by physician and satisfaction with attention given by physician, range: very satisfied to very dissatisfied. Participants answering "satisfied" or "very satisfied" to both questions were considered satisfied with their patient-physician relationship

Social support

Perceived social support measured using 6 questions. Score constructed and discrete version of the variable composed using median as cut-off point ${ }^{\ddagger}$ (median $=5$ )

*Questions used in 1998 in l'Enquête de Santé Québec sur les habitudes de vie et la santé des québécois (an enquiry into lifestyle and health of Quebec residents); ${ }^{\dagger}$ Questions that are usually the object of interventions in asthma education clinics; ${ }^{\ddagger}$ The median value was put in the lower group; ${ }^{\S}$ The median value was put in the higher group; "A provincially run local community centre offering basic primary health care and social services of preventive or curative nature and rehabilitation or integration services to the population it serves. CDC Centers for Disease Control and Prevention

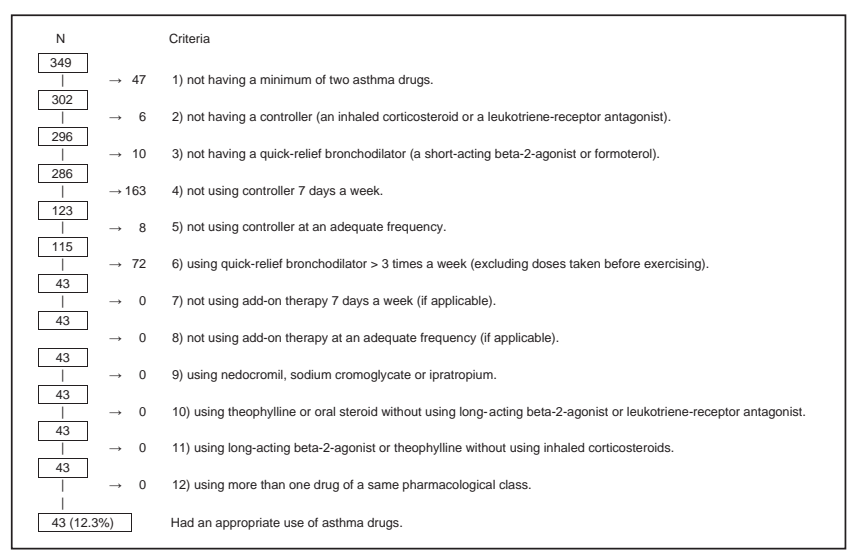

Figure 1) Total number of respondents not fulfilling each criterion and total number appropriately using asthma drugs according to the full set of criteria

previous year due to a lack of money may, indeed, have been more likely to be adherent to their treatment in the seven days before the interview. This observation may reflect the fact that inhaled corticosteroids are far more expensive than short-acting beta- 2 agonists. Individuals who use their inhaled corticosteroids regularly are more likely to report having been short of drugs at some point in the previous year due to a lack of money, simply because they had to spend more money buying drugs. Further research is, however, needed to better understand the significance of this result.
We also observed that individuals who had consulted a specialist during the preceding year for an asthma-related problem were more likely to report appropriate use of their asthma drugs. It has been observed that asthmatic patients treated by a specialist - as opposed to those treated by a general practitioner - are more likely to be dispensed drugs (25), and less likely to underuse inhaled corticosteroids $(13,15,16)$ or to overuse bronchodilators $(16,25)$. The better use of drugs observed in specialists' patients, as in our study, might be explained by a greater awareness of guideline recommendations in specialists as opposed to general practitioners. Consequently, specialists may be more likely than general practitioners to treat and educate their patients in accordance with guideline recommendations, which, in turn, translates into more appropriate use of asthma medication.

Finally, side effects were not a variable associated with self-reported appropriate (or inappropriate) use of asthma drugs. In a previous investigation studying the adherence of new users of antihypertensive drugs (24), we observed that perceived side effects were associated with discontinuation of the initial drug treatment. On the other hand, perceived side effects were not associated with noncompliance as selfreported by those who were adherent users (26). In the current study, individuals were selected based on their current use of asthma drugs. They were, therefore, more likely to be individuals who adhered to their asthma drug regimen over time. Our observation that the perception of side effects is not associated with self-reported appropriate use of asthma drugs is, therefore, consistent with what has been observed in hypertension.

We assessed the appropriateness of use of asthma drugs as selfreported by participants. In contrast to the use of administrative databases or pharmacy records, self-reported use is not necessarily based 
TABLE 2

Characteristics of the study population, unadjusted OR for each independent variable and adjusted OR for independent variables retained in the final logistic regression model $(n=349)$

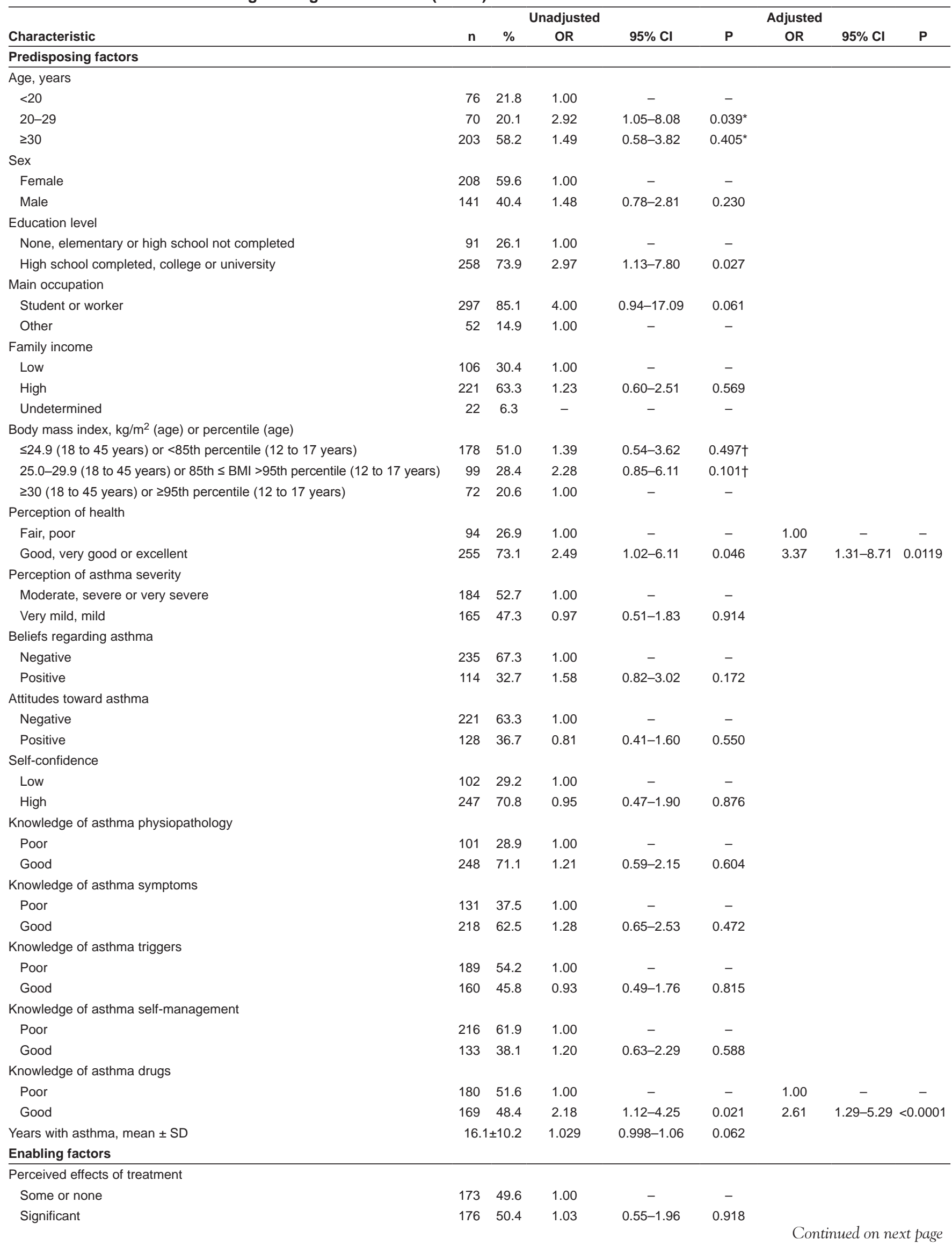


TABLE 2 - CONTINUED

Characteristics of the study population, unadjusted OR for each independent variable and adjusted OR for independent variables retained in the final logistic regression model $(n=349)$

\begin{tabular}{|c|c|c|c|c|c|c|c|c|}
\hline \multirow[b]{2}{*}{ Characteristic } & \multicolumn{4}{|c|}{ Unadjusted } & \multicolumn{3}{|c|}{ Adjusted } & \multirow[b]{2}{*}{$\mathbf{P}$} \\
\hline & $\mathbf{n}$ & $\%$ & OR & $95 \% \mathrm{Cl}$ & $\mathbf{P}$ & OR & $95 \% \mathrm{Cl}$ & \\
\hline \multicolumn{9}{|l|}{ Enabling factors } \\
\hline \multicolumn{9}{|l|}{$\begin{array}{l}\text { Perception of risks of dying due to asthma if drug taken as directed } \\
\text { by physician }\end{array}$} \\
\hline No risk & 170 & 48.7 & 0.73 & $0.38-1.39$ & 0.338 & & & \\
\hline Moderate, high or very high risk & 179 & 51.3 & 1.00 & - & - & & & \\
\hline \multicolumn{9}{|l|}{$\begin{array}{l}\text { Perception of risks of dying due to asthma if drug not taken as directed } \\
\text { by physician }\end{array}$} \\
\hline No risk & 116 & 33.2 & 1.00 & - & - & & & \\
\hline Moderate, high or very high risk & 233 & 66.8 & 1.52 & $0.74-3.14$ & 0.257 & & & \\
\hline \multicolumn{9}{|l|}{ Self-reported side effects } \\
\hline Yes & 95 & 27.2 & 1.00 & - & - & & & \\
\hline No & 254 & 72.8 & 0.96 & $0.47-1.96$ & 0.913 & & & \\
\hline \multicolumn{9}{|l|}{ Short of drugs due to a lack of money } \\
\hline No & 293 & 84.0 & 1.00 & - & - & 1.00 & - & - \\
\hline Yes & 56 & 16.0 & 2.30 & $1.10-4.83$ & 0.026 & 2.78 & $1.26-6.17$ & 0.0116 \\
\hline \multicolumn{9}{|l|}{ Ease in obtaining appointment with physician } \\
\hline Difficult or have not seen the professional during the preceding year & 152 & 43.6 & 1.00 & - & - & & & \\
\hline Easy & 197 & 56.4 & 0.78 & $0.41-1.49$ & 0.456 & & & \\
\hline \multicolumn{9}{|l|}{ Ease in obtaining information on asthma from pharmacist } \\
\hline Difficult or have not seen the professional during the preceding year & 252 & 72.2 & 1.00 & - & - & & & \\
\hline Easy & 97 & 27.8 & 0.88 & $0.42-1.82$ & 0.729 & & & \\
\hline \multicolumn{9}{|l|}{ Ease in obtaining information on asthma from nurse } \\
\hline Difficult or have not seen the professional during the preceding year & 327 & 93.7 & 1.00 & - & - & & & \\
\hline Easy & 22 & 6.3 & 0.70 & $0.16-3.10$ & 0.636 & & & \\
\hline \multicolumn{9}{|l|}{ Ease in obtaining information on asthma from respiratory therapist } \\
\hline Difficult or have not seen the professional during the preceding year & 317 & 90.8 & 1.00 & - & - & & & \\
\hline Easy & 32 & 9.2 & 1.75 & $0.67-4.52$ & 0.250 & & & \\
\hline \multicolumn{9}{|l|}{ Ease in obtaining information on asthma from other health professionals } \\
\hline Difficult or have not seen the professional during the preceding year & 330 & 94.6 & 1.00 & - & - & & & \\
\hline Easy & 19 & 5.4 & 1.36 & $0.38-4.87$ & 0.637 & & & \\
\hline \multicolumn{9}{|l|}{ Possession of written action plan } \\
\hline No & 297 & 85.1 & 1.00 & - & - & & & \\
\hline Yes & 52 & 14.9 & 1.62 & $0.73-3.61$ & 0.239 & & & \\
\hline \multicolumn{9}{|l|}{ Daily or weekly use of peak flow meter } \\
\hline No & 343 & 98.3 & 1.00 & - & - & & & \\
\hline Yes & 6 & 1.7 & $<0.001$ & $<0.001->999.999$ & 0.986 & & & \\
\hline Vaccination against influenza in past 12 months & & & & & & & & \\
\hline No & 241 & 69.1 & 1.00 & - & - & & & \\
\hline Yes & 108 & 30.9 & 1.93 & $1.01-3.70$ & 0.047 & & & \\
\hline Vaccination against pneumonia in past 12 months & & & & & & & & \\
\hline No & 334 & 95.7 & 1.00 & - & - & & & \\
\hline Yes & 15 & 4.3 & 1.10 & $0.24-5.05$ & 0.903 & & & \\
\hline Ever tested for allergies & & & & & & & & \\
\hline No & 124 & 35.5 & 1.00 & - & - & & & \\
\hline Yes & 225 & 64.5 & 1.31 & $0.66-2.62$ & 0.439 & & & \\
\hline Ever had lung function test & & & & & & & & \\
\hline No & 112 & 32.1 & 1.00 & - & - & & & \\
\hline Yes & 237 & 67.9 & 1.43 & $0.69-2.96$ & 0.331 & & & \\
\hline Ever obtained written information on asthma from health professional & & & & & & & & \\
\hline No & 277 & 79.4 & & 1.00 & - & & & \\
\hline Yes & 72 & 20.6 & 1.19 & $0.56-2.55$ & 0.649 & & & \\
\hline Ever had inhalation technique verified by health professional & & & & & & & & \\
\hline No & 232 & 66.5 & 1.00 & - & - & & & \\
\hline Yes & 117 & 33.5 & 1.07 & $0.55-2.10$ & 0.840 & & & \\
\hline Ever attended asthma education clinic & & & & & & & & \\
\hline No & 304 & 87.1 & 1.00 & - & - & & & \\
\hline Yes & 45 & 12.9 & 1.11 & $0.44-2.80$ & 0.824 & & & \\
\hline
\end{tabular}


TABLE 2 - CONTINUED

Characteristics of the study population, unadjusted OR for each independent variable and adjusted OR for independent variables retained in the final logistic regression model $(n=349)$

\begin{tabular}{|c|c|c|c|c|c|c|c|c|}
\hline \multirow[b]{2}{*}{ Characteristic } & \multirow[b]{2}{*}{$\mathbf{n}$} & \multicolumn{3}{|c|}{ Unadjusted } & \multicolumn{3}{|c|}{ Adjusted } & \multirow[b]{2}{*}{$\mathbf{P}$} \\
\hline & & $\%$ & OR & $95 \% \mathrm{Cl}$ & $\mathbf{P}$ & OR & $95 \% \mathrm{Cl}$ & \\
\hline \multicolumn{9}{|l|}{ Enabling factors } \\
\hline \multicolumn{9}{|c|}{$\begin{array}{l}\text { Consulted general practitioner during preceding year for asthma-related } \\
\text { problems }\end{array}$} \\
\hline No & 149 & 42.7 & 1.00 & - & - & & & \\
\hline Yes & 200 & 57.3 & 0.84 & $0.44-1.59$ & 0.589 & & & \\
\hline \multicolumn{9}{|c|}{ Consulted specialist during preceding year for asthma-related problems } \\
\hline No & 275 & 78.8 & 1.00 & - & - & - & 1.00 & - \\
\hline Yes & 74 & 21.2 & 1.74 & $0.86-3.54$ & 0.125 & 2.28 & $1.05-4.97$ & 0.0373 \\
\hline \multicolumn{9}{|c|}{ Reinforcing factors } \\
\hline \multicolumn{9}{|c|}{ Coherence of information } \\
\hline Low & 73 & 20.9 & 1.00 & - & - & & & \\
\hline High & 276 & 79.1 & 1.41 & $0.60-3.32$ & 0.426 & & & \\
\hline \multicolumn{9}{|c|}{ Satisfaction with physician care } \\
\hline Low & 82 & 23.5 & 1.00 & - & - & & & \\
\hline High & 267 & 76.5 & 1.02 & $0.48-2.16$ & 0.968 & & & \\
\hline \multicolumn{9}{|l|}{ Social support } \\
\hline Low & 188 & 53.9 & 1.00 & - & - & & & \\
\hline High & 161 & 46.1 & 0.91 & $0.48-1.74$ & 0.784 & & & \\
\hline
\end{tabular}

${ }^{*}$ Global $P=0.0755$ (degrees of freedom $=2$ ); ${ }^{\dagger}$ Global $P=0.1896$ (degrees of freedom $=2$ )

on the assumption that drugs purchased by individuals are actually taken. However, criticism is occasionally levelled at self-reports because they may be influenced by social desirability and the lack of patient knowledge regarding their drugs. One would expect appropriateness of drug use to be overestimated if the popular perception is that asthma drugs - in particular, inhaled corticosteroids - should be used on a regular basis. Because a rather low proportion of appropriate use was observed in our study, social desirability may not be an important issue. On the other hand, asthma - contrary to other chronic conditions - is often perceived as an intermittent disease, and many asthmatic patients are of the opinion that they should take their drugs only when symptomatic (27). Thus, reporting regular use of asthma medications may not be perceived as socially desirable. If this were the case, the proportion of appropriate use in the present population may have been underestimated.

The present study has some major strengths. A stringent set of criteria was used to assess appropriateness of use; therefore, it can be confidently stated that the use of drugs as self-reported by individuals classified as appropriately using their asthma drugs is, indeed, 'appropriate'. We evaluated the overall use of anti-asthma drug treatment, which provides a better assessment of quality of use than that provided in studies focusing solely on inhaled corticosteroids or on short-acting beta- 2 agonists. Finally, the assessment of factors likely to predict asthma drug use was organized using the PRECEDE (Predisposing, Reinforcing and Enabling Constructs in Educational Diagnosis and Evaluation) model (18). Using this conceptual framework to identify and classify factors led to a comprehensive and theory-based assessment.

It should be mentioned that, due to our criteria being especially stringent and reflecting an almost perfect adherence to asthma drugs, some participants may have been wrongly classified as inappropriately using their asthma drugs. This number, however, is likely to be low because a reassessment of the appropriateness of use of asthma drugs using a less stringent set of criteria increased the proportion of appropriate use by only $4 \%$. Therefore, we are confident that participants classified as inappropriately using their asthma drugs were actually not adherent to their controller medication and that misclassification should not be an important issue.

Even if our conceptual model assumes that predisposing, enabling and reinforcing factors precede the health behaviour, the cross-sectional design of the study did not allow us to establish the precedence of the independent variables on drug use. Hence, precedence of the associated factors must be assumed because it has not been verified.

The present study was designed to assess the appropriateness of antiasthma drug use, and to identify the factors associated with appropriate use. The recruitment of individuals through pharmacies and subsequent telephone interviews allowed us to study many potential correlates that otherwise could not have been examined using information available in administrative databases.

The finding that sound patient knowledge of their drugs may translate into better use reflects the need for physicians and pharmacists to identify asthmatic individuals who may benefit from targeted patient counselling, especially those exhibiting the characteristics identified in the present study. Pharmacists have an opportunity to provide patient-oriented pharmaceutical care at each prescription refill and, therefore, are key professionals in educating asthmatic subjects about their drugs. To conclude, the present study highlights a major need to develop and implement effective interventions to improve the appropriate use of anti-asthma medications.

ACKNOWLEDGEMENTS: The authors thank Michel Gaudet, MSc, Caty Blanchette MSc and Éric Demers MSc, for assistance in data analysis, Line Guénette $\mathrm{PhD}$, for coordinating the study and Johanne Vidal for assistance in editing the text. They also thank Isabelle Dubreuil, Patrick Tremblay, Gabriel Cloutier, Joseph Moisan-De Serres, Émilie Moisan-De Serres and Olivette Welsh for conducting the interviews and for data entry.

INSTITUTION AT WHICH THE WORK WAS PERFORMED: Unité de recherche en santé des populations, Centre hospitalier affilié universitaire de Québec.

DISCLOSURE: L-P Boulet has received honoraria to attend advisory Boards for AstraZeneca, Altana, GlaxoSmithKline (GSK), Merck Frosst and Novartis, received lecture fees from 3M, AstraZeneca, GSK, Merck Frosst and Novartis, sponsorship for basic research from 3M, Altana, AstraZeneca and Merck Frosst, funding for participating in multicentre studies of the treatment of asthma from 3M, Altana, AsthmaTx, AstraZeneca, Boehringer-Ingelheim, Dynavax, Genentech, 
GSK, IVAX, Merck Frosst, Novartis, Roche, Schering and Topigen and received support for the production of educational materials from AstraZeneca, GSK and Merck Frosst. In the past five years, Dr Moisan and Dr Grégoire have received research support from Bristol-MyersSquibb Canada, Eli Lilly \& Co USA, Merck Frosst Canada and Novartis Pharma AG. Dr Grégoire has consulted for Jannsen-Ortho Canada and Novartis Canada. E Dorval is a former employee of Merck Frosst Canada.

\section{REFERENCES}

1. Canadian Institute for Health Information, Canadian Lung Association, Health Canada, Statistics Canada. Respiratory disease in Canada. Ottawa: Health Canada, 2001:33-44.

2. Masoli M, Fabian D, Holt S, Baeasley R. Global burden of asthma. Wellington, New Zealand: Medical Research Institute of New Zealand, 2004:119.

3. Partridge MR, van der Molen T, Myrseth SE, Busse WW. Attitudes and actions of asthma patients on regular maintenance therapy: The INSPIRE study. BMC Pulm Med 2006;6:13.

4. Soriano JB, Rabe KF, Vermeire PA. Predictors of poor asthma control in European adults. J Asthma 2003;40:803-13.

5. Chapman KR, Ernst P, Grenville A, Dewland P, Zimmerman S. Control of asthma in Canada: Failure to achieve guideline targets. Can Respir J 2001;(Suppl 8):A:35A-40A.

6. Krahn MD, Berka C, Langlois P, Detsky A. Direct and indirect costs of asthma in Canada, 1990. CMAJ 1996;154:821-31.

7. Weiss KB, Sullivan SD. The health economics of asthma and rhinitis. I. Assessing the economic impact. J Allergy Clin Immunol 2001;107:3-8.

8. de Marco R, Cazzoletti L, Cerveri I, et al. Are the asthma guideline goals achieved in daily practice? A population-based study on treatment adequacy and the control of asthma. Int Arch Allergy Immunol 2005;138:225-34.

9. Blais R, Grégoire JP, Rouleau R, Cartier A, Bouchard J, Boulet LP. Ambulatory use of inhaled b2-agonists for the treatment of asthma in Quebec: A population-based utilization review. Chest 2001;119:1316-21.

10. Anis AH, Lynd LD, Wang XH, et al. Double trouble: Impact of inappropriate use of asthma medication on the use of health care resources. CMAJ 2001;164:625-31.

11. Shireman TI, Heaton PC, Gay WE, Cluxton RJ, Moomaw CJ. Relationship between asthma drug therapy patterns and healthcare utilization. Ann Pharmacother 2002;36:557-64.

12. Adams RJ, Fuhlbrigge A, Finkelstein JA, et al. Impact of inhaled anti-inflammatory therapy on hospitalization and emergency department visits for children with asthma. Pediatrics 2001;107:706-11.

13. Diette GB, Wu AW, Skinner EA, et al. Treatment patterns among adult patients with asthma: Factors associated with overuse of inhaled beta-agonists and underuse of inhaled corticosteroids. Arch Intern Med 1999;159:2697-704.

14. Zuckerman IH, Stuart B, Madger LS, Bollinger ME, Weiss SR. Adherence to asthma treatment guidelines among children in the Maryland medicaid program. Curr Ther Res Clin Exp 2000;61:912-24.

15. Legorreta AP, Christian-Herman J, O'Connor RD, Hasan MM, Evans R, Leung KM. Compliance with national asthma

\section{COMPETING INTERESTS: None declared.}

FUNDING: This research was supported by a grant from the Réseau québécois de l'asthme et de la MPOC under the auspices of the program: "Towards Excellence in Asthma Management" program. The sponsor had no involvement in the conduct of the study.

management guidelines and specialty care: A health maintenance organization experience. Arch Intern Med 1998;158:457-64.

16. Meng YY, Leung KM, Berkbigler D, Halbert RJ, Legorreta AP. Compliance with US asthma management guidelines and specialty care: A regional variation or national concern? J Eval Clin Pract 1999;5:213-21

17. Adams RJ, Fuhlbrigge A, Guilbert T, Lozano P, Martinez F. Inadequate use of asthma medication in the United States: Results of the asthma in America national population survey. J Allergy Clin Immunol 2002;110:58-64.

18. Green LW, Kreuter MW. Health Promotion Planning: An Educational and Environmental Approach, 2nd edn. Mountain View: Mayfield Publishing Company, 1991:427

19. Lemière $C$, Bai T, Balter $M B$, et al. Adult asthma consensus guidelines update 2003. Can Respir J 2004;11(Suppl A):9A-18A.

20. Belsley D, Kuh E, Welsch R. Regression diagnostics: Identifying influential data and sources of collinearity. New York: Wiley, 1980.

21. SAS Institute Inc. SAS OnlineDoc, Version 9.1. Cary, USA. 2004

22. Hong SH, Sanders BH, West D. Inappropriate use of inhaled short acting beta-agonists and its association with patient health status. Curr Med Res Opin 2006;22:33-40.

23. Farber HJ, Capra AM, Finkelstein JA, et al. Misunderstanding of asthma controller medications: Association with nonadherence. J Asthma 2003;40:17-25.

24. Grégoire J-P, Moisan J, Guibert R, et al. Determinants of discontinuation of new courses of antihypertensive medications. J Clin Epidemiol 2002;55:728-35.

25. Schatz M, Zeiger RS, Mosen D, et al. Improved asthma outcomes from allergy specialist care: A population-based cross-sectional analysis. J Allergy Clin Immunol 2005;116:1307-13.

26. Gregoire J, Moisan J, Guibert R, Ciampi A, Milot A. Predictors of self-reported noncompliance with antihypertensive drug treatment: A prospective cohort study. Can J Cardiol 2006;22:323-9.

27. Chambers CV, Markson L, Diamond JJ, Lasch L, Berger M. Health beliefs and compliance with inhaled corticosteroids by asthmatic patients in primary care practices. Respir Med 1999;93:88-94.

28. World Health Organization. Obesity: preventing and managing the global epidemic. Report of a WHO Consultation. Geneva: World Health Organization. 2000. Report No: WHO Technical Report (Series 894).

29. Prevention CfDCa. CDC Growth Charts: United States. Hyattsville, Maryland: National Center for Health Statistics, U.S. Department of Health and Human Services. 2000. Report No: 314. 


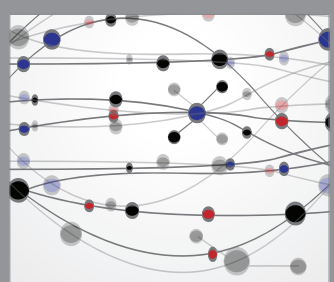

The Scientific World Journal
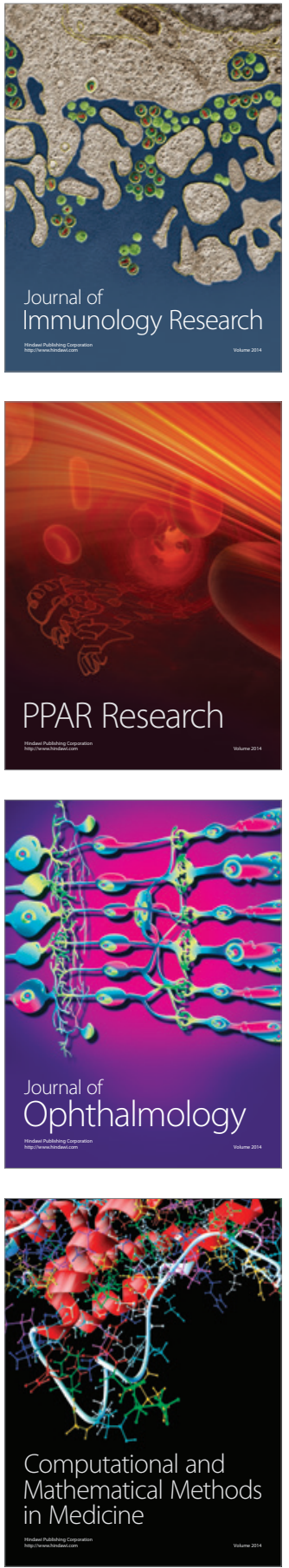

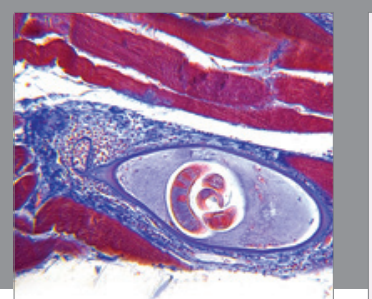

Gastroenterology Research and Practice

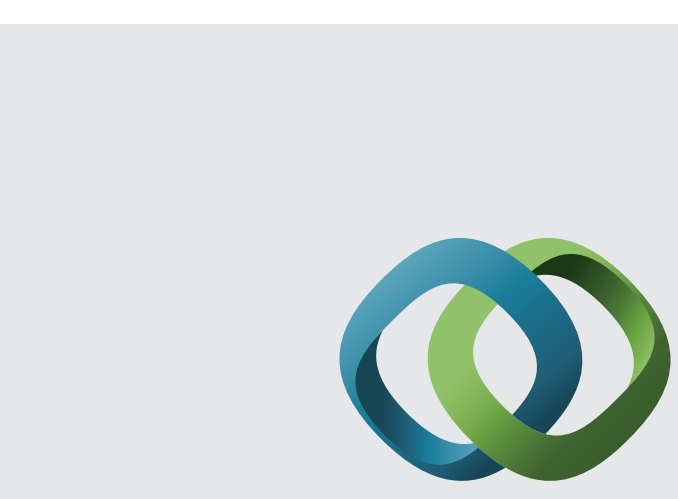

\section{Hindawi}

Submit your manuscripts at

http://www.hindawi.com
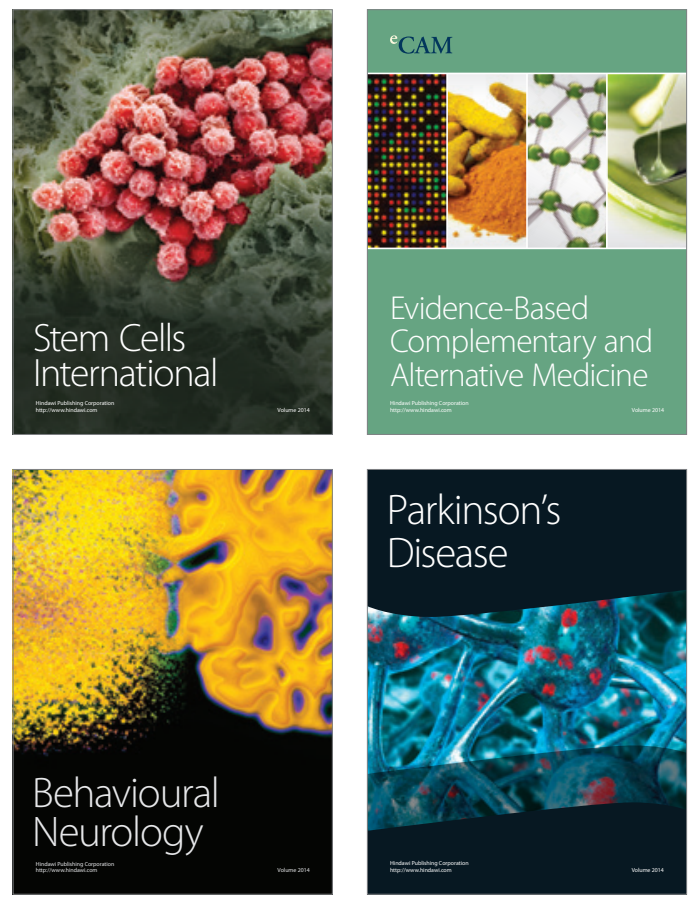
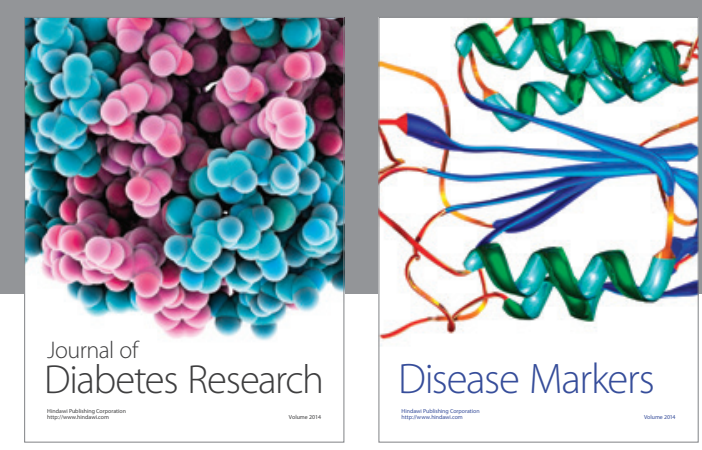

Disease Markers
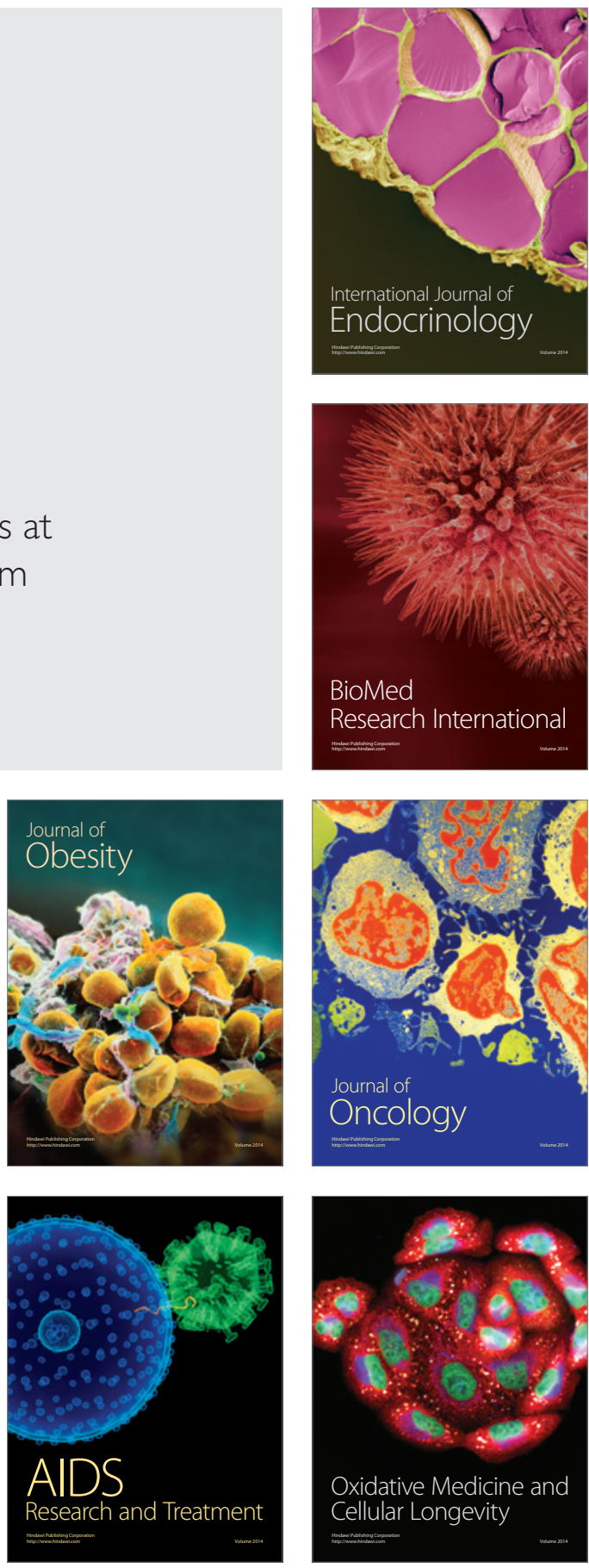